\title{
Assistência de enfermagem humanizada ao paciente em UTI
}

\author{
Humanized nursing care to the patient in ICU
}

Asistencia de enfermería humanizada para el paciente en la UCl

\begin{abstract}
Resumo: Hoje em dia a humanização é ponto de pauta nos encontros nacionais e internacionais da área da saúde. Assim, cada vez mais enfermeiros nas unidades de terapia intensiva tem se preocupado com a sua prática. O presente estudo foi desenvolvido com o objetivo de compreender, reconhecer e entender como o comportamento humanizado reflete ao paciente e identificar a percepção da equipe de enfermagem sobre o processo de humanização. Trata-se de uma pesquisa de revisão bibliográfica descritiva com análise qualitativa, os dados foram coletados nas Bases de Dados de Enfermagem (BDENF) da Biblioteca Virtual de Saúde (BVS) e livros publicados no período de 2009 a 2012. O ambiente de cuidados em UTI precisa ser acolhedor, integrador e estimulador para todos os envolvidos no processo de cuidado e/ou sob o cuidado. A humanização não tem data e nem momento certo para acontecer, devendo estar presente em todas as ações dos profissionais no cuidado ao paciente, a despeito das barreiras encontradas. A educação permanente é uma importante aliada que pode contribuir de forma positiva para assistência humanizada.
\end{abstract}

Descritores: Enfermagem, Humanização, Unidade de Terapia Intensiva.

\begin{abstract}
Today, the humanization is point to agenda in national and international meetings in the field of health. Thus, more and more, nurses in intensive care units were been concerned with its practice. The present study was aimed to understand, recognize how the behavior humanized reflects in the patient and identify the perception of the nursing staff on the process of humanization. This is a bibliographic survey with descriptive and qualitative analysis data were collected in the Basis of Data of Nursing (BDENF) of the Virtual Health Library (BVS) and books published between 2009 and 2012. The environment of care in the ICU needs to be welcoming, inclusive and stimulating for all involved in the care and/or under the care. Humanization is undated and not the right time to happen, and should be present in all the actions of the professionals in patient care, despite the barriers encountered. Continuing education is an important tool that can contribute positively to the humanized.
\end{abstract}

Descriptors: Nursing, Humanization, Intensive Care Unit.

Resumen: Hoy es el orden del día el punto humanización en reuniones nacionales e internacionales en el campo de la salud. Por lo tanto, más y más enfermeras en las unidades de cuidados intensivos se ha preocupado con su practica. El presente estudio tuvo como objetivo comprender, reconocer y entender cómo el comportamiento humanizado refleja el paciente e identificar la percepción del personal de enfermería en el proceso de humanización. Se trata de un estudio de analisis cualitativo descriptivo bibliográfica, se recogieron datos sobre la Base de Datos de Enfermería (BDENF) de la Biblioteca Virtual en Salud (BVS) y los libros publicados entre 20092012. El entorno de los cuidados en la UCl debe ser acogedor, integrador y estimulante para todos los involucrados en el cuidado y/o bajo el cuidado. La humanización no tiene fecha y no el momento adecuado para pasar, y debe estar presente en todas las acciones de los profesionales en la atención al paciente, a pesar de los obstáculos encontrados. La educación continua es una herramienta importante que puede contribuir positivamente a humanizado.

Descriptores: Enfermería, Humanización, Unidad de Cuidados Intensivos.

Claudir Aparecido Vieira Enfermeiro. Formado pela Faculdade Mario Schenberg. E-mail: vieiraclaudir@terra.com.br

Luiz Faustino dos Santos Maia

Enfermeiro. Mestre em Terapia Intensiva pela SOBRATI. Especialista em Saúde Coletiva e Saúde da Família; Gestão e Auditoria dos Serviços de Enfermagem; Enfermagem em Urgência, Emergências e Cuidados Intensivos pela UNICSUL; Programa Especial de Formação Pedagógica em Ciências Biológicas pela UNINOVE; Docência do Ensino Médio, Técnico e Superior na Área da Saúde pela FAPI. Docente de graduação em Enfermagem pela FMS. Coordenador Geral da Revista Recien. 


\section{I ntrodução}

A humanização em unidade de terapia intensiva (UTI) significa cuidar do paciente de maneira holística, englobando o contexto familiar e social. Esta prática deve incorporar os valores, as esperanças, os aspectos culturais e as preocupações de cada um.

Nesta era de globalização, onde o conhecimento é o principal fator de produção, tratar este recurso tornase uma atividade prioritária dentro de uma empresa, uma vez que existe uma competição bastante acirrada no mercado. Em relação à saúde, a situação não é diferente, pois os profissionais de áreas específicas sentem cada vez mais a necessidade de compartilhar novos conhecimentos, em busca da diferenciação, da projeção no mercado e dos melhores resultados em suas equipes de trabalho ${ }^{1}$.

Com as profundas desigualdades socioeconômicas que ainda o caracterizam, o acesso aos serviços e aos bens de saúde com consequente responsabilização de acompanhamento das necessidades de cada usuário permanece com graves lacunas e precisa de mudanças. A esse quadro acrescente se também a desvalorização dos trabalhadores de saúde, a expressiva precarização das relações de trabalho, o baixo investimento num processo de educação permanente desses trabalhadores, a pouca participação na gestão dos serviços e o frágil vínculo com os usuários².

Culturalmente a UTI é um ambiente desconhecido e incerto, que traz aos pacientes e familiares, uma ideia de gravidade associada com a perda, que, muitas vezes não condiz com a realidade. A internação na UTI é um momento que normalmente desencadeia estresse, tanto aos pacientes e familiares quanto à equipe de enfermagem ${ }^{3}$.

A UTI sendo um ambiente que em sua maioria concentram pacientes, que necessitam de monitorização contínua, apesar de dispor de assistência médica e de enfermagem direcionadas, e de equipamentos vitais e sofisticados; insere o enfermo a um ambiente hostil, com exposição intensa a estímulos dolorosos, onde a luz contínua, os procedimentos clínicos invasivos estão presentes em sua rotina de cuidados.
Com as novas tecnologias em saúde, especialmente na área da enfermagem intensiva, implicou um redimensionamento do espaço do cuidado, imprimindo mudanças gradativas nos cuidados prestados pelo enfermeiro e sua equipe. Requerendo dos profissionais habilidades, como cuidador, na observação, comunicação, reflexão, aplicação dos conhecimentos científicos, além de se fazerem apreciações e tomada de decisões.

Nas unidades de cuidados intensivos, por abrigarem pacientes críticos ou de alto risco, que necessitam de cuidados diretos e contínuos, pois seu quadro de saúde pode facilmente evoluir para a morte, é determinante a presença de pessoal treinado e em número suficiente para que se estabeleçam adequados tratamento e cuidado ${ }^{4}$.

Para que haja maior valorização e humanização entre as necessidades de cuidados dos pacientes durante sua jornada de trabalho, o profissional em saúde de enfermagem, justificar a necessidade de um maior número de pessoal permanentemente na equipe, treinados e capazes de realizar suas funções que the são confiadas.

Cabe destacar as condições de trabalho são muito importantes para a humanização do cuidado, principalmente em unidade de terapia intensiva (UTI), contudo é preciso investir na melhoria do atendimento. Às vezes, no ambiente hospitalar, existe máquinas de última geração e faltam medicamentos e materiais para procedimentos, como luvas, seringas, agulhas, ou para a lavagem das mãos, o que é fundamental para o controle da infecção.

Executar a função de receptor e informador transcende as atitudes de preencher papéis e dizer para onde ir ou o que fazer. Essa afirmação é fundamental para que todos os profissionais, que estarão em contato com o enfermo, estejam preparados para dar todo tipo de atenção, cuidado e apoio. Os profissionais necessitam de uma preparação desde o momento da escolha da profissão, quando se pensou que um dia gostaria de ajudar as pessoas ${ }^{5}$.

O processo de humanização das relações no ambiente da terapia intensiva deve ser sempre uma preocupação dos gestores e dos profissionais da saúde por envolver a compreensão do significado da vida do ser humano. À medida que vai se acrescentando novas tecnologias nas UTIs, é exigida maior qualificação dos profissionais para operá-las com precisão, segurança e eficácia, preservando 
com toda essa tecnologia os valores éticos e humanísticos que norteiam a profissão ${ }^{6}$.

A justificativa para a realização deste estudo foi baseada na relatividade de constatar se existe uma falta de informação sobre a humanização por parte dos profissionais de enfermagem que trabalham em UTI.

\section{Objetivo}

Compreender, reconhecer e entender como o comportamento humanizado reflete ao paciente.

Identificar a percepção da equipe de saúde sobreo processo de humanização.

\section{Material e Método}

Trata-se de uma pesquisa de revisão bibliográfica descritiva com análise qualitativa.

Os dados foram coletados nas bases de dados de Enfermagem (BDENF), da Biblioteca Virtual de Saúde (BVS) e livros.

Foram selecionados artigos publicados na fonte e que atendem aos seguintes critérios de inclusão: estavam disponíveis e completos; possuíam como idioma de publicação o português; foram publicados no período de 2008 a 2012

Foram excluídos os artigos que não atendem a qualquer um dos critérios de inclusão.

\section{Resultados e Discussão}

Na realidade social brasileira da década de 1980 predominava a exclusão do direito à saúde para a maioria dos cidadãos. Esse era restrito aos trabalhadores que contribuíam para o Instituto Nacional de Previdência Social, prevalecendo à lógica contraprestacional e da cidadania regulada. A partir de 1983 observaram-se ações efetivas de um movimento em busca de transformação dessa realidade, liderado por representantes da sociedade, intelectuais, trabalhadores da saúde e alguns políticos que já discutiam estas questões, iniciando assim uma luta pelos direitos à cidadania, dentre eles a saúde ${ }^{7}$.

$\mathrm{Na}$ esteira deste processo democrático constituinte, o chamado movimento sanitário tinha proposições concretas. A primeira delas, a saúde como direito de todo - cidadão, independente de ter contribuído, ser trabalhador rural ou estar desempregado. Esse movimento culminou com a VIII Conferência Nacional de Saúde no ano de $1986^{7}$.

A UTI surgiu da necessidade de oferecer suporte e tratamento a pacientes potencialmente graves, que tenha chances de sobreviver. Sendo uma unidade de monitoramento e vigilância contínua. O ambiente da UTI pode ser considerado fonte de estresse, que envolve tanto paciente quanto a equipe de saúde, podendo gerar distúrbios psíquicos e fisiológicos. Humanizar depende unicamente de cada pessoa do comprometimento com o próximo com o mundo em que os rodeia, proporcionando com essas ações uma assistência humanizada ${ }^{8}$

O ambiente de cuidados em UTI precisa ser acolhedor, integrador e estimulador para todos os envolvidos no processo de cuidado e/ou sob o cuidado. Tanto os profissionais e gestores, como os pacientes e seus familiares precisam sentir-se parte integrante desse ambiente, a fim de formar uma rede de relações e interações dinâmica e sensível às singularidades humanas ${ }^{9}$.

A UTI é uma unidade muito complexa e parece ser um ambiente à parte do hospital. Sendo assim, pode dar a impressão que é uma unidade independente dentro hospital, embora esteja extremamente interligada e dependente do mesmo. No entanto, a UTI necessita continuamente de diversos serviços de apoio do próprio hospital, que dão suporte contínuo, ininterrupto e prioritário à UTI ${ }^{9}$.

É necessário humanizar a assistência na unidade de terapia intensiva e isso somente acontecerá quando se estabelecer o diálogo genuíno entre cuidadores, familiares e pacientes. $O$ interesse por parte da equipe de enfermagem evidenciado nesta pesquisa em ajudar o outro num processo de cuidado priorizando pela conservação e cuidado do ser na especificidade mais humana possível, em um momento de fragilidade e único da sua vida, independente do estado em que se encontra, abre horizontes para que possamos repensar nossa prática diária no processo de cuidar, de tornar esta interação mais humana ${ }^{10}$.

Falar em humanização é fácil, o difícil é concretizar na prática, porque envolve o comportamento humano e a 
singularidade no fazer. A equipe de enfermagem identifica e percebe formas de humanização nos horários de visitas preconizadas, no ser empático, na estrutura da instituição, que oferece solário, televisão e posto de enfermagem centralizado. E também reconhece que existem fatores que causam dificuldades na humanização como falta da educação permanente e sobre carga de trabalho ${ }^{11}$.

A humanização não tem data e nem momento certo para acontecer, devendo estar presente em todas as ações dos profissionais no cuidado ao paciente, a despeito das barreiras encontradas. Tal fato demonstra a dificuldade dos sujeitos em saber mobilizar sua rede de recursos e transpô-los para sua prática e esse saber deve ser incentivado ${ }^{12}$.

Nesse contexto, pensar em um ambiente de UTI adequado para o cuidado integral e humanizado ao paciente, que compreende tecnologias diferenciadas e profissionais técnicos e humanamente qualificados, implica apreender a complexidade em suas diferentes dimensões, aspectos, eventos e movimentos que compõem o cuidado em UTI. No entanto, essa complexidade precisa transcender o modelo de assistência biologicista, linear, pontual e fragmentado, no qual o ser humano é visto em partes fragmentadas ${ }^{9}$.

Para atender às múltiplas dimensões e aspectos do cuidado ao ser humano, torna-se necessário a utilização de novos referenciais, capazes de envolverem a complexidade e a integralidade do cuidado no ambiente complexo e dinâmico de UTI. Assim, é preciso desenvolver uma visão ampliada do conjunto de elementos que compõe esse ambiente, com base em uma visão sistêmica e global ${ }^{9}$.

A implantação do cuidado humanizado na UTI e qualquer medida tomada no intuito de melhorar a qualidade do atendimento trarão benefícios aos pacientes e consequentemente à instituição. Humanizando o cuidado, toda equipe será beneficiada, pois seu trabalho implica em resultados positivos ao tratamento, e recuperação do paciente ${ }^{10}$.

o cuidado não se restringe somente a técnica, no fazer, mas também no sentido de ser, de expressar uma atitude, pois existe uma relação entre a equipe de enfermagem, paciente e família. Esta esfera de cuidado passará a ser humanizada quando houver envolvimento dos cuidadores com o ser doente e o familiar que compartilham a experiência, reconhecendo a singularidade dos envolvidos na relação por meio do diálogo ${ }^{13}$.

A educação permanente e a sensibilidade do cuidador, como notamos, são fatores primordiais a serem utilizados com o objetivo de suprir as necessidades relacionadas ao atendimento humanizado na UTI, por meio de um diálogo mais próximo do paciente, familiares e equipe de saúde em geral $^{10}$.

O processo de Humanização do atendimento é uma temática que exige muita reflexão, pois a integralidade da assistência não envolve somente o paciente, mas a família, a equipe de profissionais e o ambiente onde todas estas ações se estabelecem ${ }^{14}$.

Enquanto todos nós profissionais membros da equipe de saúde não nos empenharmos em prestar uma assistência mais humana, colocando-nos sempre na situação de quem está fragilizado, a procura de um tratamento de respeito, não conseguiremos prestar uma assistência humanizada ${ }^{10}$.

O cuidado humano é calçado nos princípios da ética. Isso significa valorizar os sujeitos que participam do processo de cuidar, favorecendo o desenvolvimento de sua sensibilidade e competência, reconhecendo a singularidade de cada um e seus potenciais na busca de estratégias que viabilizem um cuidado que leve à recuperação do cliente em todas as suas dimensões ${ }^{13}$.

Neste contexto, acredita-se que a construção de uma assistência humanizada em UTI é um processo com metas no curto, médio e em longo prazo, impulsionada por medidas de avaliação e da capacidade de aprender com a própria experiência e a dos outros.

\section{Conclusão}

Este presente estudo possibilitou realizar uma discussão baseada na humanização no ambiente da terapia intensiva, sob a luz do pensamento sistêmico/complexo.

Observamos que os profissionais de enfermagem defendem humanização como respeito pelo ser humano, assistir ao paciente de forma holística e valorizar o paciente e sua família. 
Humanização no ambiente da terapia intensiva é uma preocupação dos profissionais da saúde por envolver a compreensão do significado da vida do ser humano.

A empatia é uma importante característica que possibilita aos profissionais um fazer diferenciado com vistas na humanização da assistência e à medida que novas tecnologias vêm se incorporando às UTIs, é exigida uma maior qualificação dos profissionais para operá-las com precisão, segurança e eficácia.

Alguns aspectos podem influenciar na humanização da UTI, como: uma adequada área física, a garantia da visita diária em mais de um turno, ter recursos humanos em quantidade suficiente e com capacitações periódicas, além dos mesmos atuarem em sintonia e com respeito mútuo.

Portanto cabe ao profissional analisar sua prática, suas habilidades e limitações, aliar às teorias, às questões éticas implicadas na garantia dos direitos dos pacientes, para tornar a assistência de enfermagem humanizada e de qualidade.

Humanização na UTI proporciona uma melhora nas práticas cuidadosas, um cuidado comprometido com a ética, o diálogo e a autonomia do paciente e de sua família.

Possibilitar uma maior participação da família no cuidado ao paciente, e que a equipe pode ser solidária no desenvolvimento dos cuidados, respeitando a individualidade do paciente e de cada família, respeitando suas crenças e costumes.

Um simples bom dia, perguntar como passou a noite, se esta se alimentando, e buscando em cada resposta do paciente uma nova forma de tranquiliza-lo para sua estadia em um ambiente desconhecido.

Entretanto, esta pesquisa não teve a pretensão de esgotar todas as possibilidades de estratégias da humanização em UTI, mas, através de seu efeito, permitir uma reflexão e até mesmo a ação de ousar em recomendar aos profissionais da saúde a importância de estarem atentos para intervir nas lacunas existentes de interrelações, dentro do cenário chamado de unidade de terapia intensiva desenvolver as práticas assistenciais de humanização.
A educação permanente é uma importante aliada que pode contribuir de forma positiva para assistência humanizada.

Concluímos que devemos estar preparados cientificamente para as mudanças tecnológicas sem abandonar o respeito e a humanização para com o nosso cliente, analisarmos e colocarmos em pratica um pouco mais de nossos conhecimentos e não devemos simplesmente olhar, analisar uma determinada situação e não fazer nada para sua melhora ou mudança.

Portanto amar e se dedicar ao próximo, é praticar humanização consigo mesmo.

\section{Referências}

1. Martins TG. Mapeamento de capitais para o estudo de viabilidade de um curso móvel de desenvolvimento em CTI/UTI pediátrica. Rio de Janeiro. 2003.

2. Queijo AF, Padilha KG. Nursing Activities Score- NAS: adaptação transcultural e validação para a língua portuguesa. Rev. Esc. Enferm USP. 2009; 43:1009-1016.

3. Silva MJP. Qual o tempo do cuidado? Humanizando os cuidados de Enfermagem. São Paulo: Loyola, 2009.

4. Silva RC, Ferreira MA. A tecnologia em saúde: uma perspectiva psicossociológica aplicada ao cuidado de enfermagem. Rev. Esc. Anna Nery. 2009; 13(1):169-173.

5. Fones AFN. Propostas para uma melhor adaptação do paciente ao meio hospitalar. Psicópio: Revista Virtual de Psicologia Hospitalar e da Saúde. Belo Horizonte. 2009; 4(8). Disponível em: <http://www.scielo.br>. Acesso em 15 mai 2013.

6. Costa SC, Figueiredo MRB, Schaurich D. Humanização em unidade de terapia intensiva adulto (UTI): compreensões da equipe de enfermagem. Botucatu: Interface - Comunicação, Saúde, Educação. 2009; 13(1).

7. Fundação Oswaldo Cruz - FIOCRUZ. Escola Nacional de Saúde Pública Sergio Arouca. Assistência farmacêutica em foco no Estado do Rio de Janeiro: normas e documentos para ação. 2009. Disponível em: <http://www.ensp.fiocruz.br>. Acesso em 02 jun 2013.

8. Assunção PG, Fernandes AR. Humanização no atendimento ao paciente idoso em unidade de terapia intensiva: análise da literatura sobre a atuação do profissional de saúde. 2009. Disponível em: <www.scielo.br>. Acessado em 03 mai 2011. 
9. Backes MTS, Backes DS, Erdmann AL. Relações e interações no ambiente de cuidados em Unidade de Terapia Intensiva. São Paulo: Acta paul. enferm. 2012; 25(5).

10. Maffasioli C, Kammler NN. Cuidado humanizado na unidade de terapia intensiva adulto. Centro Universitário FEEVALE. 2009. Disponível em: <http://ged.feevale.br>. Acesso em 01 mai 2012.

11. Lemos JS, Filus WA. Humanização em unidade de terapia intensiva: percepção da equipe de enfermagem. 2011. Disponível em: <http://www.corenpr.org.br>. Acesso em 07 jun 2013.
12. Oliveira NES, Oliveira LMAC. Humanização do cuidado em terapia intensiva: saberes e fazeres expressos por enfermeiros. 2012. Disponível em: <http://mestrado.fen.ufg.br/uploads>. Acesso em 02 jun 2013.

13. Squassante ND, Alvim NAT. Relação equipe de enfermagem e acompanhantes de clientes hospitalizados: implicações para o cuidado. Brasília: Rev Bras Enferm. 2009; 62(1): 11-7.

14. Goulart BNG, Chiari BM. Humanização das práticas do profissional de saúde - contribuições para reflexão. Rio de Janeiro: Ciênc. saúde coletiva. 2010; 15(1). 